\title{
APLICAÇÃO DE MATERIAIS ALTERNATIVOS PARA O USO DA ENERGIA SOLAR
}

\author{
M. C. MACEDO NETO', I. R. B. GOMES ${ }^{2}$, Z. J. SANTOS JÚNIOR ${ }^{1}$, E. V. OLIVEIRA ${ }^{1}$ e L. G. M. SOUZA \\ ${ }^{1}$ Instituto Federal de Educação, Ciência e Tecnologia do Rio Grande do Norte \\ ${ }^{2}$ Universidade Federal do Rio Grande do Norte \\ miguel.cabral@ifrn.edu.br
}

Artigo submetido em setembro/2011 e aceito em agosto/2014

DOI: $10.15628 /$ holos.2014.663

\section{RESUMO}

Sabe-se que a maioria das tecnologias e fontes energéticas utilizadas atualmente, além de não serem renováveis, não são ecologicamente corretas. Nesse contexto, o uso de tecnologias alternativas para preservação do meio ambiente se faz necessário. Este artigo descreve a construção de um coletor solar constituído de materiais alternativos de baixo custo para aquecimento de água, no qual a viabilidade térmica e econômica será avaliada.

PALAVRAS-CHAVE: Coletor solar, materiais alternativos, baixo custo.

\section{ALTERNATIVE MATERIALS TO SOLAR ENERGY USE}

\section{ABSTRACT}

It has been known that most of the technologies and energetic sources currently used are neither renewable nor eco-friendly. Then, the use of alternative technologies for keeping the environment is necessary.
This article describes the building of a solar collector made by low cost alternative materials for water heating in which the thermal and economical viability will be evaluated.

KEYWORDS: Solar collector, alternative materials, low cost. 


\section{INTRODUÇÃO}

O sol é fonte de energia renovável. O aproveitamento desta energia tanto como fonte de calor, quanto de luz, é uma das alternativas energéticas mais promissoras para enfrentarmos os desafios do novo milênio.

A energia solar é abundante e permanente, renovável a cada dia, não polui e nem prejudica o ecossistema. A energia solar é a solução para áreas afastadas e ainda não eletrificadas, especialmente num país como o Brasil onde se encontram bons índices de insolação em qualquer parte do território. (YAKOV, 2000)

A energia solar soma características vantajosas positivas para o sistema ambiental, pois o Sol, trabalhando como um imenso reator à fusão, irradia na terra todos os dias um potencial energético extremamente elevado e incomparável a qualquer outro sistema de energia, sendo a fonte básica e indispensável para praticamente todas as fontes energéticas utilizadas pelo homem.

As aplicações mais difundidas da tecnologia solar referem-se a conversão da radiação solar em energia térmica, e em energia elétrica. Podemos citar:

- Aquecimento de água;

- Secagem de produtos agrícolas;

- Geração de vapor;

- Refrigeração;

- Conversão fotovoltaica: bombeamentos, iluminação, refrigeração, etc.

Com a ênfase dada à questão ambiental, que atinge caráter de imprescindibilidade quando se busca meios de amenizar os efeitos do nefasto aquecimento global, o mundo desenvolvido prioriza a utilização das energias limpas e renováveis. Nesse contexto a energia solar tem merecido um destaque especial, com todos os países criando programas de incentivo a sua utilizando, abrindo linhas de financiamento com baixas taxas de juros e subsidiando os preços de aquisição de tais equipamentos (TRENDS IN RENEWABLE ENERGIES, 2006; YAKOV, 2000).

O aquecimento de água por meio da utilização de coletores solares tem representado, juntamente com as células fotovoltáicas, conversoras da energia solar em energia elétrica eletricidade, uma das aplicações mais viáveis de utilização, tanto residencial quanto industrial (LORENÇO, 2001).

O nordeste brasileiro apresenta um potencial solar bastante significativo, correspondente a uma disponibilidade média que se situa na faixa de 500 a $700 \mathrm{~W} / \mathrm{m}^{2}$, conforme Atlas de Irradiação Solar do Brasil (BEZERRA, 2001). Segundo o Balanço Energético Nacional (BEN) de 2003, 42 \% do consumo de energia elétrica no Brasil é direcionado para o setor de edificações, sendo 84,1\% correspondente a empresas e residências e 15,9 \% a administração pública público, com cifras alcançando 13,8 \% do Produto Interno Bruto do país (VARELLA, 2004).

O setor residencial responde por $23 \%$ do consumo nacional de energia e de acordo com manual de uma companhia de energia do Brasil o consumo do chuveiro elétrico é o segundo maior em uma residência, correspondendo a $25 \%$, perdendo apenas para o refrigerador/freezer que 
corresponde a $30 \%$. Sua utilização atinge o horário de pico das 18:00 às 19:00 horas, correspondendo a 8,5 \% da demanda nacional de energia neste horário (VARELLA,2004).

Estes dados apontam a importância da substituição da fonte térmica elétrica pela fonte solar, para a obtenção de água quente principalmente em tempo de racionamento de energia, ganhando contornos de imprescindibilidade uma vez que a opção hídrica brasileira para a geração de energia elétrica está praticamente com seus recursos exauridos. (SOUZA, 2002).

Os dispositivos utilizados para a produção de água quente por meio da utilização da energia solar são os coletores que podem ser divididos em dois grupos os planos e os alternativos, sendo os planos mais utilizados. Tais coletores geralmente são constituídos por tubos absorvedores de cobre, chapa absorvedora de cobre ou alumínio, cobertura de vidro e isolamento térmico de lã de vidro e a grade absorvedora é confeccionada na configuração em paralelo. ( SOUZA, 2002).

O objetivo de ser construir e ser utilizar um coletor é de se usar com ele uma Energia Solar limpa não poluente, e que, portanto, não agride o meio ambiente. O Aquecedor solar não depende de concessionárias ou distribuidoras de energia, nem sofre tributação, o que contribui para o barateamento no seu uso. (SOUZA, 2002).

\section{REVISÃO BIBLIOGRÁFICA}

Olhando para o futuro, perceber-se-á que o custo da energia tenderá a ser sempre maior e a crise de combustíveis fósseis e de madeira tornar-se-á mais e mais aguda. As formas de suprimento de energia estão determinando o curso dos desenvolvimentos social e econômico futuros. O suprimento de energia será a base para um elevado e sustentável nível de segurança e conforto. A energia também determinará o balanço ecológico. (LORENÇO, 2001).

As tecnologias e fontes energéticas que se usam nos dias atuais influenciarão significativamente o amanhã. Há também uma grande evidência de que a maioria das tecnologias energéticas em uso não é ecologicamente apropriada e tem o potencial de provocar sérias e irreversíveis mudanças climáticas, bem como a constatação de que a quase totalidade destas fontes energéticas não é renovável e estão se esgotando rapidamente. Em função dessas percepções, o direcionamento às fontes renováveis de energia é inevitável. As fontes de energia eólica, solar e de biomassa são abundantes, amplamente distribuídas e ecologicamente atrativas. Essas fontes não poluem a atmosfera e não contribuem para o aumento da temperatura do planeta. (LORENÇO, 2001).

As características especiais das energias renováveis que as tornam atrativas são: uso e produção descentralizada, envolvendo um grande número de produtores e consumidores e custo inicial relativamente mais alto comparado a sistemas convencionais, mas de baixo custo de manutenção. (SOUZA, 2002)

\subsection{A importância da energia solar}

Cada metro quadrado da superfície do sol emite cerca de 62,8 MW de energia eletromagnética, que são lançados no espaço. A origem desta energia está em um conjunto de reações termonucleares que ocorrem no núcleo do sol causando uma diminuição em sua massa da ordem de 4,25 milhões de toneladas em cada segundo. Embora esse dado seja avaliado como 
uma perda inimaginável seriam necessários 147 bilhões de anos (a idade de nosso sistema solar é estimada em 8 bilhões de anos) de atividade solar, neste mesmo ritmo, para que a sua massa sofresse uma diminuição de um por cento (1\%) (BEZERRA, 2001). Para se ter uma idéia de tal potencial basta que se faça a seguinte análise (SOUZA, 2002): Considere-se que a terra recebe do sol, a nível do solo, no máximo $1 \mathrm{~kW} / \mathrm{m}^{2}$, embora possa atingir maiores picos em algumas localidades. Excluídas as regiões Ártica e Antártica, ela recebe em média cerca de $3,6 \mathrm{kWh} / \mathrm{m}^{2}$.dia.

As massas continentais, excluídas as regiões Ártica e Antártica, possuem uma área de cerca de $132,5 \times 10^{12} \mathrm{~m}^{2}$. Portanto, a incidência solar sobre essas massas continentais é $4,77 \times$ $10^{8} \mathrm{GWh} /$ dia. Logo, a incidência em um ano é de $1,74 \times 10^{11} \mathrm{GWh}$.

Considerando-se que o consumo energético anual atual corresponde a $1,5 \times 10^{8} \mathrm{GWh}$, conclui-se que a energia solar disponível nas massas continentais representa mais de 1.000 vezes o consumo de energia da humanidade. Isso equivale a dizer que menos de $1 \%$ da energia solar disponível nas massas continentais seria suficiente para suprir de energia à humanidade. Considerando-se toda a área da terra, a disponibilidade aumenta para $1,02 \times 10^{13} \mathrm{GWh}$.

Uma vez que a luz solar está disponível em todas as regiões da terra e pode ser usada de forma descentralizada, a opção solar para a geração de eletricidade dispensa o caro transporte da energia por meio de redes de distribuição, inerentes ao sistema convencional.

Os equipamentos solares têm um grande potencial em países tropicais, entre os quais se encontra o Brasil, com disponibilidade equivalente a $1,13 \times 10^{10} \mathrm{GWh}$, por possuírem significativos potenciais solares e receberem energia solar em quase todo o ano, como acontece no nordeste brasileiro.

A radiação solar é atualmente usada para produzir potência por meio de duas tecnologias: fotovoltaica e térmica. A tecnologia fotovoltaica tem um grande potencial e parece ser um dos mais atrativos modos de obtenção de energia no futuro. Os sistemas fotovoltaicos são atualmente mais confiáveis e econômicos que muitas outras tecnologias energéticas por serem independentes, descentralizados e pelas alternativas de aplicabilidade, gerando uma gama de produtos para consumo.

Um sistema fotovoltaico pode atuar em rede ou de modo independente. São muito importantes para o desenvolvimento de países do terceiro mundo, pela escassez de fornecimento de energia elétrica principalmente em áreas rurais, onde a energia elétrica gerada pode ser usada de forma descentralizada.

Os métodos para a geração de potência térmica solar são essencialmente os mesmos das tecnologias convencionais, porém o combustível usado é a energia térmica. Ao invés do combustível fóssil, usa-se a radiação solar. A faixa de temperatura requerida para aplicações domésticas e comerciais pode ser coberta com as tecnologias disponíveis de conversão da energia solar em energia térmica.

Os sistemas térmicos solares para uso principalmente doméstico não necessitam de alta eficiência, porém para uso em aplicações industriais e comerciais já estão sendo desenvolvidos sistemas de alta performance. Tais sistemas permitem a obtenção de temperaturas para préaquecer a água de alimentação de caldeiras, aquecer água e ar em processos industriais e produzir vapor para gerar potência. 


\subsection{Os coletores alternativos}

Os coletores alternativos têm se constituído na principal linha de pesquisa no âmbito do Laboratório de Máquinas Hidráulicas e Energia Solar da UFRN, já tendo sido desenvolvidas, construídas e estudadas várias gerações destes tipos de coletor. Busca-se, de forma prioritária, o barateamento do custo de fabricação de um sistema de aquecimento de água solar.

Estes coletores foram objetos de estudo de quatro dissertações de mestrado, apresentadas ao Programa de Pós-Graduação em Engenharia Mecânica da UFRN. A seguir far-se-á uma breve discussão sobre a história deste tipo de coletor, a nível mundial e local, mostrando os resultados alcançados por várias de suas gerações e as análises que conduziram ao desenvolvimento do presente trabalho.

\subsubsection{Os coletores alternativos no mundo}

O principal objetivo do estudo de coletores alternativos é a redução do custo de fabricação, buscando a socialização do seu uso em sistemas de aquecimento de água doméstico e industrial, uma vez que o custo dos mesmos representa $50 \%$ do custo total de investimento para a aquisição de um sistema solar para aquecimento de água.

Em 1980, BAYAZTTOGLU e ASGARPOUR descreveram estudo para calcular o desempenho performance de coletores tubulares que usavam bulbos de vidro envolvendo tubos absorvedores, com as unidades aquecedoras evacuadas. HERRICK, em 1982, apresentou estudo sobre medidas ópticas de transmitância em um coletor solar composto por tubos de vidro cilíndricos. Em 1997, TSILINGIRIS propôs um coletor solar baseado no mesmo princípio, porém incluindo um coletor fechado feito com um material isolante térmico e estrutura rígida.

Os aquecedores solares domésticos de água (SDHW) são largamente utilizados atualmente para a produção de energia térmica solar a baixas temperaturas. Estes tipos de coletores têm sido objeto de numerosos estudos e pesquisas desde 1950. WILLIER e Hottel (1958) E Bliss (1959), estudaram pela primeira vez o desempenho térmico de coletores com tubos paralelos e suas conclusões serviram de base para muitas pesquisas posteriores.

Rivera (1994), apresentou trabalho sobre coletor alternativo tubular com múltiplas unidades absorvedoras de PVC. Lourenço, em 1997, mostrou os resultados alcançados com um coletor alternativo com grade absorvedora formada por múltiplos tubos de alumínio. Ambos demonstraram as viabilidades térmicas e econômicas de tais coletores, comprovando a competitividade dos mesmos em relação aos coletores convencionais.

O coletor em estudo foi ensaiado em regime de fluxo forçado com somente uma passagem do fluido no interior do coletor, como também para várias passagens, por meio do uso de um sistema de bombeamento de baixa vazão. Foi demonstrado que o melhor desempenho foi obtido com o coletor atravessado por uma única passagem.

O coletor que usava tubos absorvedores de pvc revelou-se mais viável e mais competitivo em relação ao coletor convencional.

O uso de um polímero absorvedor foi estudado por VAN NIEKERK et al., em 1996, com o objetivo de avaliar o desempenho de coletores com tubos paralelos na África do Sul. A variação geométrica de parâmetros tais como o diâmetro dos tubos, o espaçamento entre tubos e as 
dimensões da caixa foram estudadas para a otimização do desempenho dos mesmos. VAN NIEKERK et al., concluíram que a melhor configuração foi obtida para um espaçamento entre tubos igual a zero. Isso demonstra que a configuração da placa plana do coletor é o parâmetro que mais afeta o seu desempenho.

Matraway e Farkas, (1997), compararam um coletor com duas placas paralelas (TPPC), com, respectivamente, um coletor com tubos paralelos (PTC) e um coletor com tubos em serpentina (STC). Sob o mesmo ambiente e condições de desempenho, a eficiência do TPPC foi respectivamente 6,0 e $10 \%$ maior que o STC e PTC.

SHAH, em 1999 apresentou estudo sobre a modelagem térmica em coletores domésticos para aquecimento de água à baixa vazão.

CRISTOFARI, et al., propuseram em 2002, estudar uma configuração de coletor que apresenta uma performance similar à proposta por Hottel e Willier (1958); Willier ( 1977), Bliss (1959) e Matraway e Farkas ( 1997), mas que difere principalmente: por utilizar um novo material para a caixa do coletor, que se caracteriza por ter baixa condutividade térmica, ser mais resistente à corrosão, ter baixo peso e menor custo; por ter uma geometria retangular de passagem de fluxo para aumentar sua rigidez; e por utilizar uma nova metodologia de cálculo onde a capacidade calorífica de vários componentes é levada em conta, permitindo uma simulação dinâmica do comportamento do sistema.

O uso de coletores com tubos para absorção de polipropileno e placas de absorção de polietileno de alta densidade é bastante enfocado pela literatura. Esses coletores são usados para aquecimento e climatização de piscinas (CENSOLAR, 1999, GIL,2001).

\section{Energia Solar Fototérmica}

Está diretamente ligado na quantidade de energia que um determinado corpo é capaz de absorver, sob a forma de calor, a partir da radiação solar incidente no mesmo. A utilização dessa forma de energia implica saber captá-la e armazená-la. Os coletores solares são equipamentos que tem como objetivo específico de se utilizar a energia solar fototérmica.

Os coletores solares são aquecedores de fluídos (líquidos ou gasosos) e são classificados em coletores concentradores e coletores planos em função da existência ou não de dispositivos de concentração da radiação solar. O fluído aquecido é mantido em reservatórios termicamente isolados até o seu uso final (água aquecida para banho, ar quente para secagem de grãos, gases para acionamento de turbinas, etc.).

Os coletores solares planos são largamente utilizados para aquecimento de água em residências, hospitais, hotéis etc. devido ao conforto proporcionado e à redução do consumo de energia elétrica.

\subsection{O Coletor Solar}

O coletor solar difere do painel fotovoltaico porque utiliza a energia solar para aquecer um fluido (em geral a água) e não para gerar eletricidade.

O coletor solar é o coração do sistema de aquecimento solar. Ele é o dispositivo responsável pela absorção e transferência da radiação solar para um fluido sob a forma de energia térmica. São 
muito utilizados no aquecimento de água de casas ou edifícios, hospitais, piscinas, secagem de grãos, para refrigeração de ambientes e processos industriais de aquecimento.

De modo geral, o coletor solar funciona recebendo radiação solar e a transfere para a placa absorvedora. O calor é então transferido para o fluido que escoa no interior de tubos que estão em contato com a superfície absorvedora.

\subsection{Desenvolvimento de Coletores Solares Alternativos no LES/UFRN}

Buscando formas de obtenção de um sistema de aquecimento a baixo custo, vem-se estudando há mais de 18 anos no âmbito do Laboratório de Energia Solar da Universidade Federal do Rio Grande do Norte sistemas alternativos para tornar viável o uso da energia solar para o fim considerado e torná-lo acessível a uma maior parcela da população.

\section{PROCEDIMENTO EXPERIMENTAL}

\subsection{Componentes}

Um sistema de aquecimento solar exige um projeto térmico que utiliza os seguintes componentes:

- Coletores solares;

- Reservatórios isolados termicamente;

- Circuitos para o controle da circulação forçada e de acionamento do sistema anticongelador;

\subsection{Construção do coletor}

O processo de construção deste coletor seguiu as seguintes etapas:

1) Construção do molde da caixa;

2) Construção da caixa - em gesso, pó de madeira, agave e tela de arame; caixa foi confeccionado com um compósito a base de gesso, pó de madeira e fibra de sisal, três elementos de baixa condutividade térmica

3) Resinagem da caixa do coletor;

4) Construção do suporte para colocação da caixa;

5) 5.Aplicação do elemento vedante na grade absorvedora (resina);

6) Corte da lâmina de cobertura de vidro plano transparente;

O processo de montagem seguiu os seguintes passos:

1) Montagem dos tubulões de recepção e distribuição

2) Montagem da grade absorvedora

3) Pintura da grade absorvedora

4) Pintura da caixa do coletor 
5) Pintura do suporte da caixa;

6) Confecção dos furos de entrada e saída das tubulações na caixa, com serra copo;

7) Colocação do conjunto absorvedor no interior da caixa.

8) Colocação da lâmina de cobertura do coletor;

9) Aplicação de borracha de silicone para a vedação do coletor;

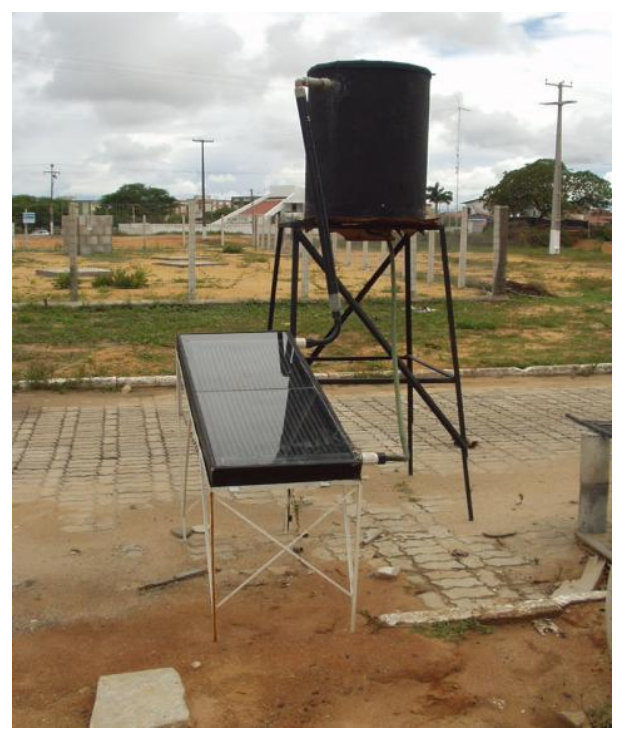

Figura 1 - Coletor solar em estudo. (SOUZA, 2002)

\subsubsection{Características:}

O coletor solar mostrado na figura 1 tem as seguintes características:

- - Transforma luz em calor;

- - Quando exposto ao sol, cada metro quadrado do coletor aquece diariamente 70 litros de água até $55^{\circ} \mathrm{C}$.

- - Sua área varia de $1,4 \mathrm{~m}^{2}$ a $2 \mathrm{~m}^{2}$;

- Armazena a água aquecida pelo coletor, podendo ser do tipo aberto (sem pressão) ou fechado (pressurizado), mas sempre isolado termicamente;

- - Seu volume deve ser ideal para as necessidades diárias de consumo de água quente do edifício onde está instalado;

Os dutos de água quente são de cobre, polipropileno ou CPVC, sempre isolados termicamente.

\subsubsection{Componentes}

Os componentes de um coletor solar como mostra a figura2. São basicamente um coletor que pode ser dividido nas seguintes partes:

- - Módulo: Geralmente fabricado de alumínio, suporta e protege todo os componentes do coletor. 
- - Cobertura: Geralmente de vidro, permite a passagem de radiação solar e reduz a perda de calor para o meio.

- - Vedação: É essencial para que não haja interferências externas e para que não se perca calor para o meio ambiente. Também impede a entrada de umidade, grande responsável pela acentuada e acelerada degradação de alguns dos componentes do coletor solar (tinta e isolamento). É aconselhável a utilização de silicone para se fazer a vedação entre o módulo e o vidro.

- - Tubulação: Tubos interconectados por meio dos quais o fluido escoa no interior do coletor. Geralmente a tubulação é feita de cobre devido à sua grande condutividade térmica, facilitando a transferência de calor entre a placa absorvedora e o fluido.

- Placa absorvedora: é o componente mais importante do coletor solar plano. É responsável pela absorção e transferência da energia solar para o fluido. Metais que possuem alta condutividade térmica como alumínio e cobre são comumente utilizados como materiais absorvedores.

- Geralmente esta placa é pintada com tintas de cores escuras, especialmente preto, à base de poliéster, acrílico ou epoxi para uma melhor absorção de radiação solar.

- - Isolamento térmico: Os isolantes são materiais com condutividade térmica baixa, colocados abaixo da placa absorvedora e nas laterais de modo a minimizar as perdas pôr condução. Deste modo, ficam em contato direto com o módulo, revestindo-o. Na maior parte das vezes, é utilizado lã de vidro ou rocha ou ainda espuma de poliuretano.

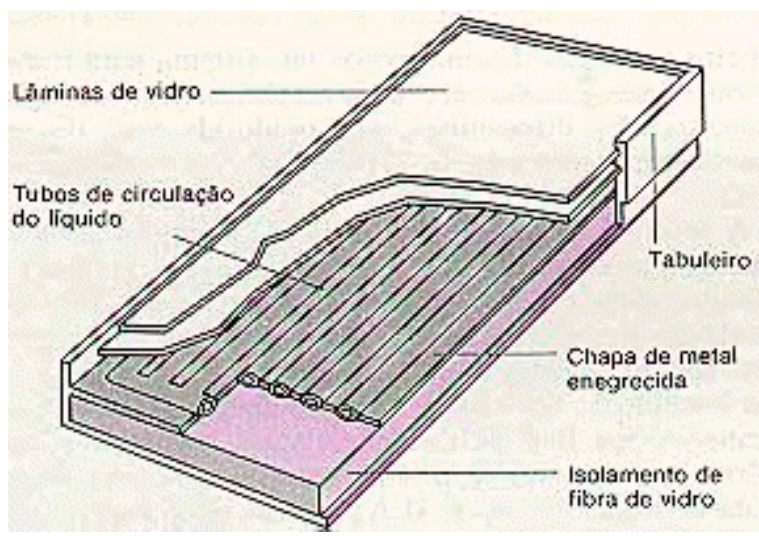

Figura 2 - Componentes do coletor solar. (SOUZA, 2000)

\subsection{Circulação da água}

O princípio de funcionamento do coletor como mostrado na figura 3, ocorre com a água que sai da caixa d'água fria e vai para o boiler, seguindo depois para as placas que estão no telhado da casa. A água é aquecida ao passar pelas placas, a água quente retorna para o boiler, ficando armazenada até o seu consumo. A água pode circular pêlos coletores por meio de duas maneiras: natural (termosifão) ou forçada 


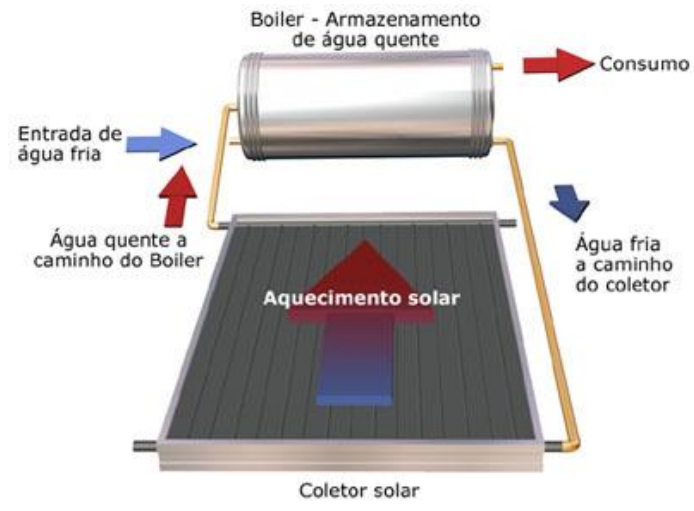

Figura 3 - Principio de funcionamento do coletor. (SOUZA,2000)

\section{RESULTADOS}

Para que os coletores tenham um ótimo aproveitamento da luz solar, é recomendado o seu posicionamento ao norte geográfico. Para a sua localização correta é necessária a utilização de uma bússola. O norte geográfico está situado sempre à direita do norte magnético e varia de acordo com o local. Para a cidade de São Paulo, o norte geográfico está a 18a à direita do norte magnético. Em geral, ele se encontra aproximadamente a 20 para o Brasil.

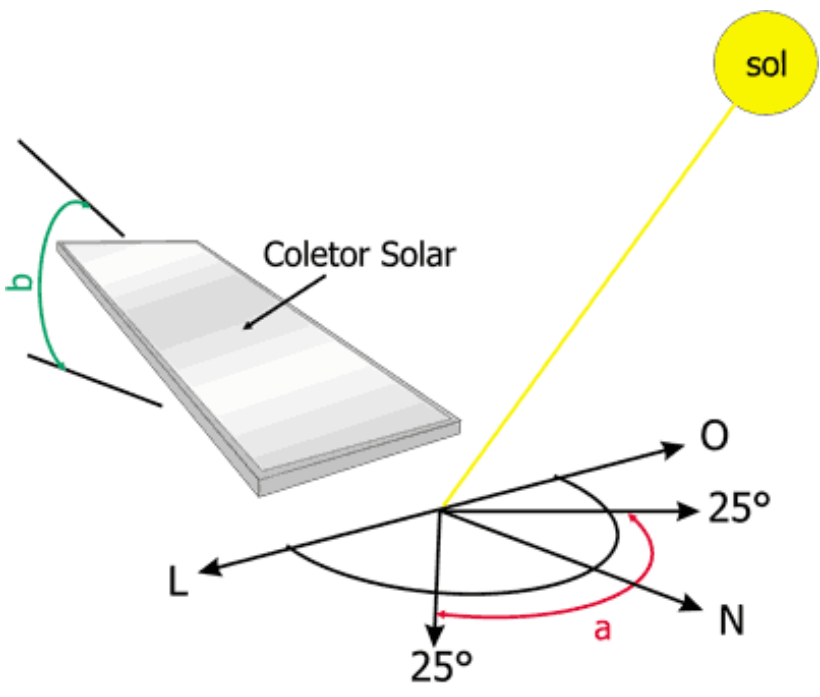

Figura 4 - Posição adequada para o uso do coletor solar (SOUZA, 2000)

Em relação ao tempo tem de retorno do dinheiro investido na compra do equipamento, com a economia de energia proporcionada pelo Aquecimento Solar, tem-se o retorno do dinheiro investido no equipamento entre 24 e 36 meses, considerando-se um consumo mensal de cerca de $220 \mathrm{kWh} / \mathrm{mês}$ (que é a média da região sudeste pôr residência). Deve se levar em conta que a vida útil estimada dos Aquecedores Solares é de 20 anos. Neste cálculo não está considerada a redução do valor de aquisição de outro equipamento para Aquecimento da água por meio de outro tipo de energia, como Aquecedores elétricos ou à gás, ou ainda chuveiros. Se considerarmos esta redução, o tempo de retorno pode reduzir e variar de 0 (zero) a 12 meses

A energia solar ao substituir a energia elétrica utilizada quando o chuveiro elétrico é ligado, reduz (ou pode reduzir), em média, 35\% do gasto em energia elétrica numa casa. 
A energia elétrica usada no aquecimento de água responde pôr $6 \%$ do consumo nacional, o dobro do destinado à iluminação pública. Em tempos de ameaça de blecaute e preocupação com o esgotamento das reservas energéticas, a economia, além de economizar dinheiro, preserva o meio ambiente $A$ abundância é outro ponto favorável.

\section{CONCLUSÕES}

A energia solar ao substituir a energia elétrica utilizada quando o chuveiro elétrico é ligado, reduz (ou pode reduzir), em média, $35 \%$ do gasto com energia elétrica numa casa. A energia elétrica usada no aquecimento de água responde pôr $6 \%$ do consumo nacional, o dobro do destinado à iluminação pública. Em tempos de ameaça de blecaute e preocupação com o esgotamento das reservas energéticas, a economia, além de economizar dinheiro, preserva o meio ambiente $A$ abundância é outro ponto favorável.

O sistema de aquecimento proposto mostrou-se muito viável em relação aos estudos térmicos, econômicos e de material, bem como à comparação de custo com sistemas similares disponíveis no mercado.

O tanque de armazenamento feito de materiais alternativos, compósitos, teve uma economia bastante significativa em relação aos tanques com outros tipos de materiais tipo o cobre.

Os materiais alternativos utilizados demonstraram que é possível a construção de um sistema que aquecimento de custo bem inferior aos convencionais disponíveis no mercado, viáveis no campo térmico e de materiais.

Além de reduzir em média $35 \%$ da conta de luz, quase não requer manutenção, apenas a limpeza semestral das placas - ela é feita com água e sabão no início ou fim do dia e não necessita de mão-de-obra especializada. A exemplo do que ocorre com os demais sistemas de aquecimento central, a temperatura não varia com a vazão. Pôr fim, o aquecedor solar não depende de concessionárias ou distribuidoras de energia nem sofre tributação. Quem constrói hoje e não planeja a sua instalação está retrocedendo.

\section{REFERÊNCIAS}

1. BAYAZTTOGLU, Y; ASPARGOUR, S., Performance Calculations of Tubular Cover Collectors, Solar Energy, 24, 105 - 109, 1980.

2. BEZERRA, A.M., Aplicações térmicas da energia solar, Editora Universitária - UFPB, João Pessoa, 2001.

3. BLISS, R.W., The derivations of several plate efficiency factors useful in the design of flat plate solar heat collectors, Solar Energy, 3, 55, 1959.

4. CABIROL, T; PELISSOU. A.; ROUX, D., El calentador solar de agua, Compañia Editorial Continental, S.A., Barcelona, Espanha, 1978.

5. CENSOLAR, La Energía Solar: Aplicaciones Prácticas, Tercera edición, Sevilla, 1999.

6. CRISTOFARI, C. Et al., Modeling and performance of a copolymer solar water heating collector, Solar Energy, v. 72: (2), p. 99-112, 2002.

7. DICKINSON, W.C., CHEREMISINOFF, P.N., Solar Energy Technology Handbook, Part B, Marcel 
Dekker, New York, 03-30, 1980.

8. GIL, M. C.; SANTOS, A.C., Energía solar térmica de baja temperatura, CENSOLAR (Centro de Estudios de la Energia Solar), PROGENSA, Sevilla, 2001.

9. HERRICK, C.S., Optical Transmittance Measurements on a Solar Collector of Cylindrical Glass Tubes, Solar Energy, 28, 5 -11, 1982.

10. HOTTEL, H.C.; WILLIER, A., Evaluation of flat plate collector performance. In: Transactions of the Conference on the Use of Solar Energy, 2, University of Arizona Press, 174, 1958.

11. LOURENÇO, J.M., Estudo de um Coletor Solar Alternativo, usando Tubos Absorvedores de Alumínio, 1997. 144f. Dissertação (Mestrado em Engenharia Mecânica) Centro de Tecnologia, Departamento de Engenharia Mecânica, Programa de Pós-Graduação em Engenharia Mecânica, Universidade Federal do Rio Grande do Norte, Natal.

12. Mano, E.B., 2000, Polímeros como Materiais de Engenharia, Edgard Blucher, São Paulo.

13. MATRAWY, K.K.; FARKAS, I., Comparison study for three types of solar collectors for water heating, Energy Convers. Manage, 38, 861-869, 1997.

14. RIVERA, D.A.L., Projeto de Construção e Análise de Desempenho de um Coletor Solar Alternativo a Baixo Custo, 1994. 127f. Dissertação (Mestrado em Engenharia Mecânica) Centro de Tecnologia, Departamento de Engenharia Mecânica, Programa de Pós-Graduação em Engenharia Mecânica, Universidade Federal do Rio Grande do Norte, Natal

15. SHAH, L.J., Investigation and Modeling of Thermal Conditions in Low Flow SDHW Systems, Department of Buildings and Energy, Technical University of Denmark, Report R-034, 1999.

16. SOUZA, L.M., 2002, Viabilidades térmica, econômica e de materiais da utilização de tubos de PVC como elementos absorvedores em coletores de um sistema de aquecimento de água por energia solar. Tese de Doutorado do Programa de Doutorado em Ciência e Engenharia de Materiais da UFRN, Natal.

17. SOUZA, L.G.M., 2000, Sistema Alternativo de Aquecimento Solar, CONEM - Natal/RN .

18. Trends in Renewable Energies, SolarAcess.com, Canadian Association for Renewable Energies, 2005-2007.

19. TSILINGIRIS, P.T., Design, analysis and performance of low-cost plastic film large solar water heating systems, Solar Energy, 60 : (5), 245-256, 1997.

20. VAN NIEKERK, W.M.K; Du TOIT, C.G.; SCHEFFLER, T.B., Performance modeling of a parallel tube polymer absorber, Solar Energy, 58, 39-44, 1996.

21. VARELLA, F.K.O.M., Tecnologia solar residencial: inserção de aquecedores solares de água no Distrito de Barão Geraldo - Campinas, Dissertação de Mestrado da Faculdade de Engenharia Mecânica da UNICAMP, Campinas-São Paulo, 2004.

22. YACOV, T., ZEMEL, A., Long-term perspective on the development of solar energy, Solar Energy, 68: (5), 379-392, 2000.

23. WILLIER, A., Prediction of performance of solar collectors. In: Applications of Solar Energy for Heating and Cooling of Buildings, ASHRAE, New York, 1977. 